\title{
"Promoting Teaching and Learning Through Competition", To build an Engineering Practice Training System Complemented by Competition and Education
}

\author{
Ding Chen*, Juan Wang, Bin Han, Zhi Qin and Shanru Chen \\ ${ }^{1}$ School of Cyberspace Security, Chengdu University of Information Technology, Chengdu 610225, China \\ "Corresponding author. Email: chending@cuit.edu.cn
}

\begin{abstract}
Under the background of "New Engineering", college students' innovation ability and engineering practice ability are the core tasks of higher education, and subject competition is an important way to cultivate college students' practical innovation ability. In order to strengthen the innovation and practical ability of students in computer-related majors, this article relies on professional discipline competition activities, through the improvement of the talent training program, integrates discipline competition into the whole process of engineering practice training, and focuses on training through the establishment of a hierarchical and phased discipline competition mechanism Students' practical and innovative abilities will improve their creativity and overall quality in an all-round way, forming a virtuous circle of "promoting teaching by competition and learning by competition".
\end{abstract}

Keywords: Subject competition, Engineering practice, Innovation ability, Practical ability.

\section{INTRODUCTION}

To realize national strategic plans such as "Made in China 2025" and "Internet +", China urgently needs modern engineering talents with diversification, strong innovation ability, professional qualities and humanistic feelings. The national education development "13th Five-Year Plan" clearly pointed out that during the "13th Five-Year Plan" period, the proportion of innovative talents will be further increased, so that students' innovative spirit and practical ability will be significantly enhanced. As the extension and expansion of theoretical teaching and practical teaching, subject competition is one of the important ways to cultivate the ability of analyzing and solving problems, teamwork spirit, and innovation and entrepreneurship. Under the background of new engineering disciplines, research how to rely on engineering practice training to better play the role of subject competition, build innovative practice platforms for students, cultivate students' engineering practice ability, engineering design ability and engineering innovation ability, and form a "competition to promote teaching, The engineering practice system of "promoting learning with competition and integrating teaching and competition" has urgent practical significance.

The Cyberspace Security College of Chengdu University of Information Technology combines its own conditions and professional characteristics, and combines different levels of discipline competitions in the "Engineering Practice" training projects in different semesters, guiding students to find and solve problems by completing competition tasks to improve engineering practice capabilities And innovative thinking. Through years of practice, a multi-level three-dimensional discipline competition system has been established, which not only supports practical teaching, but also greatly enhances the characteristics of professional education. 


\section{CURRENT STATUS OF SUBJECT COMPETITIONS}

\subsection{The Current Situation of Subject Competition}

Domestic scholars have done many researches on the cultivation of college students' innovative ability. Li Guofeng and others discussed the application of the "Trinity" innovative ability training model based on course teaching, competition projects as the carrier, and technical training as the means in Changsha University. Liu Xiaoyong explored how to build a long-term working mechanism for college students' subject competitions, and form a series, full process and branding of subject competitions. Starting from the training needs of applied talents, Miao Xinxing aims to cultivate practical and innovative ability, and explores the training mode of applied talents oriented by subject competition through the four-year continuous line mechanism. Fan Li proposed to use a multidisciplinary competition platform to promote the reform of practical teaching and promote a new mode of training innovative talents. By introducing subject competitions into typical practical teaching and extracurricular comprehensive practice, Li Ping uses active practice to let students fully experience the concept-design-implementationoperation links in product design, which is more conducive to cultivating students' comprehensive analysis ability, design ability and hands-on ability.

\subsection{The Current Problem}

Students apply and verify the theoretical knowledge learned in class through practical activities such as subject competitions to improve their comprehensive ability, which is a very meaningful process in itself. However, during the implementation of this process, the following problems were also exposed:

(1) Due to the wide variety of subject competitions, students are blinded in choosing which competitions to participate in;

(2) Subject competitions have high requirements for practice and a wide range of knowledge. The contradiction in how to transform the knowledge learned in class into application ability is highlighted;

(3) The college's lack of organization and management of competitions has resulted in low competition results;

(4) After all, there are few prizes in the competition. How to correctly evaluate and motivate the students who have not won the prize to ensure the continuity and coverage of the competition.

\section{CONSTRUCT AN ENGINEERING PRACTICE SYSTEM INTEGRATING DISCIPLINE COMPETITIONS}

After years of teaching and competition practice, for the college's network engineering, information security, and Internet of Things engineering, a set of phased and comprehensive engineering practice systems integrating discipline competitions is summarized as follows:

Engineering Practice 1, the implementation semester is in the second half of the freshman semester. Freshmen mainly focus on basic courses, and cultivate students' awareness and interest in competition by participating in the $\mathrm{C}$ language programming class competition in the college;

Engineering Practice 2, the implementation semester is in the first half of the sophomore year. Sophomore students already have a certain basic professional knowledge. Under the guidance of the teacher, students in the three majors can participate in the ACM school trial, the information security school trial, and the electronic design school trial to improve their skills for the provincial and national competitions;

Engineering Practice 3, the implementation semester is in the second half of the sophomore year. Through the training of the previous class competition and school competition, students have accumulated experience and professional skills related to the competition, and can organize and participate in the National University Computer Competition, the National University Student Information Security Competition, and the Internet of Things Application Innovation Competition;

Engineering Practice 4, the implementation semester is in the first half of the junior year. After the first two years of engineering practice training, the juniors have relatively complete professional knowledge and competition experience, and can encourage and guide students to form teams across majors and participate in the "Internet+" that requires a high degree of comprehensiveness and innovation. Undergraduate Innovation and Entrepreneurship Competition, "Challenge Cup" National College Students Extracurricular Academic Technology Competition, "Creating Youth" National Undergraduate Entrepreneurship Competition;

Engineering Practice 5, the executive semester is in the second half of the junior year. This is the time when students are about to graduate and look for a job, through school-enterprise cooperation, the business side of the organization of propositions and professional guidance training, customized training to develop students' professional skills, in preparation for the fourth year of internship and employment. 


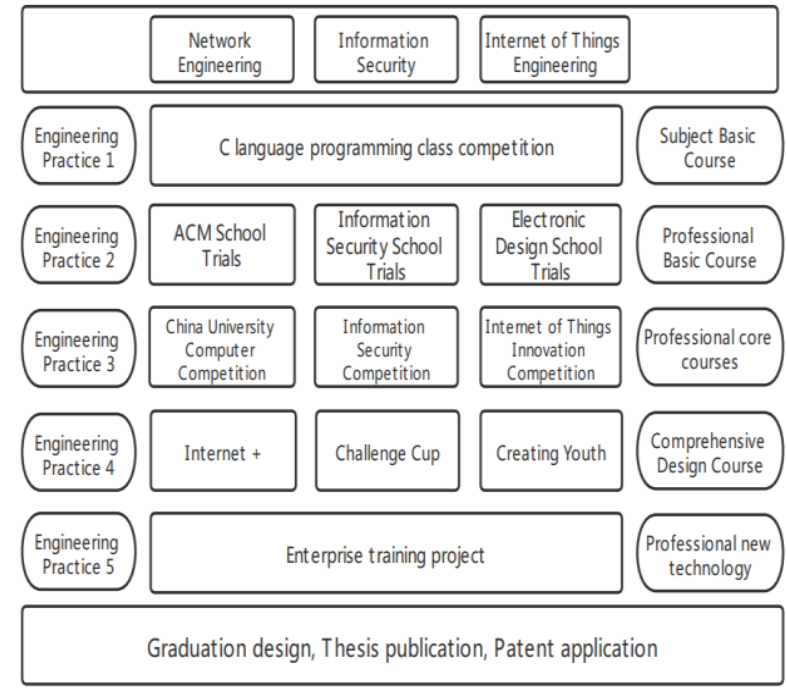

Figure 1 Engineering practice system planning integrating discipline competitions

\section{THE INSTITUTIONAL GUARANTEE FOR CONSTRUCTING AN ENGINEERING PRACTICE SYSTEM INTEGRATING DISCIPLINE COMPETITIONS}

(1) Establish the responsibility system of class tutors

Professional teachers as undergraduate class tutors are based on the foreign undergraduate tutor system, a new type of teaching management mode that gives full play to the guiding role of professional teachers to college students in daily teaching activities, and actively adapts to the development needs of my country's higher education. Professional teachers are no longer just passing on professional knowledge. While assuming class tutors, they give students targeted guidance in innovative practice, which plays an important role in the development of college students' innovative and entrepreneurial activities. In guiding students to participate in subject competitions, class tutors can help students choose and determine competition topics based on their own majors and research projects they are engaged in. In order to ensure the implementation of the class tutor system, the college takes the number of students' participation in subject competitions and competition results as one of the indicators for the performance evaluation of class tutors.

\section{(2) Establish an innovative credit system}

In order to encourage undergraduates to actively participate in science and innovation competitions, guide students to learn independently, exploratory, and practically, improve students' practical ability, enhance students' sense of innovation, and cultivate high-quality innovative talents, the college integrates disciplines into engineering practice training Competition and encourage them through the innovative credit recognition system to ensure the continuity of subject competition. According to school regulations, the grades, categories and competition rankings of subject competitions are used to determine the final scores.

\section{(3) Course practice teaching based on OBE}

The teaching process is not only a process for students to master knowledge, but also a process for students to learn to learn, gain experience, inspire creativity, stimulate exploration, and improve their abilities. Drawing lessons from the OBE engineering education philosophy, teachers use project cases to explain theoretical knowledge, and students deepen their understanding of this knowledge through the conception, design, implementation, and operation of the project. In teaching practice, through organizing discussion, students are excited to increase their perceptual knowledge, and their ability to analyze, summarize and summarize. Adopting the OBE teaching mode not only enables students to acquire basic theoretical knowledge, but also enables them to get in touch with engineering practice earlier in the process of applying knowledge to solve problems, and cultivate their practical interest and practical ability.

(4) Constructing a contingent of instructor teachers for college students' subject competitions for schoolenterprise collaborative education

In order to solve the problem that the traditional faculty is not suitable for cultivating applied engineering talents, through school-enterprise cooperation to build a faculty team, docking information industry engineering technology, promoting the combination of academic research and industrial technology, and jointly building a teaching team. Relying on the "dual-qualified" teacher team construction method, a number of teachers are arranged to go to the enterprise for further study every year to improve the teaching and research level of dualqualified teachers. Share high-level talents with wellknown companies, and hire outside technical backbones, experts and scholars to undertake some professional courses. Introduce corporate mentors, implement dual-mentor cooperative research and development projects, guide graduation projects, and guide student competition projects.

(5) Improve the reward mechanism for discipline competitions

In order to give full play to the role of the discipline competition reward mechanism, schools not only need to provide material rewards but also spiritual rewards. Set up an appropriate reward mechanism, give credit rewards, bonus rewards, and award-winning points to students who participate in subject competitions and awards, and give instructors to material rewards, title evaluation, and year-end performance evaluation bonus points. Class rewards, mobilize the enthusiasm of participating students and instructors, and encourage 
teachers and students to devote themselves to the national subject competition.

\section{CONCLUSION}

The extensive development and continuous deepening of subject competitions have not only realized the extension and sublimation of practical teaching, cultivated and improved the comprehensive quality and innovation ability of students, improved the quality of teaching and the employment rate of students, and greatly enriched the extracurricular scientific and technological activities of college students, Inspiring students' enthusiasm for scientific and technological creation.

All in all, subject competition is one of the effective ways to cultivate innovative and practical talents in applied undergraduate colleges. The school needs to build and improve the discipline competition management system from various aspects such as reward mechanism and management process according to the actual situation at this stage, so as to promote the development of students and cultivate their practical ability and innovation.

\section{AUTHORS’ CONTRIBUTIONS}

2018 "Clover Safety Cup" Sichuan Province 10th College Student Information Security Technology Competition Outstanding Instructor.

2020 "Anxun Cup" Sichuan Province 12th College Student Information Security Technology Competition Outstanding Instructor.

\section{ACKNOWLEDGMENTS}

2018-2020 Sichuan Province Higher Education Talent Training Quality and Teaching Reform Project (NO: JG2018-544).

2018-2020 Chengdu University of Information Technology first stage Education and Teaching Research and Reform Project (NO: JY2018061).

\section{REFERENCES}

[1] New Engineering Course Construction Guide [J]. Higher Engineering Education Research, 2017(4): 20-21.

[2] Sui Jinxue, Zhu Zhilin, Hua Zhen, Wang Yongqiang, Yang Li. Construction and practice of professional competition system of electrical information $[\mathrm{J}]$. China Electric Power Education, 2013(04): 129-131.

[3] Li Jijun, Zhai Yi, Du Yungang, Liu Minhua, Hu Xiuzhen. Insufficiency and improvement measures of local science and engineering colleges in national subject competitions [J]. China Modern Educational Equipment, 2016(21): 43-45.

[4] Zhang Yuping,Wang Lihua,Wang Daoyan, et al. Research and practice of undergraduates' innovative ability training model based on science and technology competition[J].Education Teaching Forum,2018,(21):141-143.

[5] Yang Jue,Zhang Wenming.Using science and technology competition as the carrier to enhance college students' innovative and practical ability [J].China Higher Education, 2014(20): 30-32.

[6] Zhang Hui, Wang Kai, Zhou Ping. Research on the Training Mode of Computer Network Professionals Oriented by Disciplinary Competition. Cultural and Educational Space, 2018, 21, Total No. 498: 157.

[7] Cheng Yi. Discussion on the Cultivation Mode of Innovative and Entrepreneurial Talents under the Background of Subject Competition [J]. Theoretical Research and Practice of Innovation and Entrepreneurship, 2019(18): 107-108.

[8] Li Ning. Discussion on the Cultivation Mode of College Students' Innovative Ability Based on Science and Technology Competition Platform [J]. Contemporary Educational Theory and Practice, $2012(6)$

[9] Xu Rong, Liu Junjian. Research on the discipline competition system integrated with professional education under the background of new engineering disciplines [J]. Journal of Chongqing Jiaotong University (Social Science Edition), 2020, 20(05): 91-97.

[10] Nie Xiaoyan, Xu Xuanwei. Reform and innovation of the new engineering school-enterprise collaborative education model $[\mathrm{J}]$. Science and Technology Wind, 2020(28): 146-147.

[11] Zhou Zhonghai, Zhu Changping, Liu Danping, Zhu Jinxiu, Yuan Minghai, Chen Bingyan. The practice of co-cultivating innovative engineering talents based on the OBE concept [J]. Laboratory Research and Exploration, 2018, 37(09): 193 $196+201$.

[12] Yan Tingting. Construction of Discipline Competition Management System in Applied Undergraduate Colleges $[\mathrm{J}]$. Science and Technology Wind, 2020(27): 185-186.

[13] Wang Rongbing,Xu Hongyan,Feng Yong.The reform and practice of the application and innovative talent training model with competition as the carrier_— taking data science and big data 
as an example[J].Journal of Liaoning University (Natural Science Edition), 2020, 47 (02):124-129.
[14] Sun Fuchun, Peng Jianshe, Tang Mao. Engineering practice quality training system for students of the "Excellence Project" [J]. Laboratory Research and Exploration, 2015, 34(05): 169-171. 